\title{
Propagação vegetativa de porta-enxertos de pereira por estacas semi-lenhosas
}

\author{
Nelson Pires Feldberg${ }^{1}$, Wilson Barbosa ${ }^{2}$, Newton Alex Mayer ${ }^{3}$, Fernanda Motta da Costa Santos ${ }^{4}$
}

\section{RESUMO}

Pesquisou-se a viabilidade técnica da propagação vegetativa dos porta-enxertos de pereira 'Taiwan Nashi-C', 'Taiwan Mamenashi' (Pyrus calleryana Dcne.) e 'Seleção IAC-1' (Pyrus spp.), por estacas semi-lenhosas. O experimento foi conduzido em telado equipado com sistema de nebulização intermitente, pertencente ao Núcleo de Pesquisa e Desenvolvimento do Jardim Botânico, do Instituto Agronômico (IAC), em Campinas, Estado de São Paulo. Adotouse o fatorial 3 x 4 (porta-enxertos x doses de ácido indolbutírico), com cinco repetições de 20 estacas, em delineamento inteiramente casualizado. Com os resultados obtidos aos 60 dias após a estaquia, conclui-se que: a) é tecnicamente possível a propagação dos porta-enxertos ‘Taiwan Nashi-C', 'Taiwan Mamenashi’ e 'Seleção IAC-1' por estacas semilenhosas; b) dentre os porta-enxertos pesquisados, 'Taiwan Nashi-C’ apresenta a maior porcentagem de enraizamento, a menor porcentagem de estacas com calo, além do maior comprimento de raízes e número de raízes por estaca; c) é necessário o uso de ácido indolbutírico para o enraizamento de estacas semi-lenhosas desses porta-enxertos, sendo que, no conjunto das variáveis analisadas, as concentrações de $4.000 \mathrm{mg} . \mathrm{L}^{-1}$ e de $6.000 \mathrm{mg} . \mathrm{L}^{-1}$ proporcionam os maiores benefícios ao enraizamento adventício; d) as concentrações de ácido indolbutírico testadas não são fitotóxicas às estacas semi-lenhosas dos genótipos pesquisados.

Palavras-chave: Estaquia, pêra, propagação clonal, Pyrus calleriana, Pyrus spp.

\section{ABSTRACT}

\section{Vegetative propagation of pear rootstocks using semi hardwood cuttings}

The objective of this work was to evaluate the technical viability of the vegetative propagation of the pear rootstocks 'Taiwan Nashi-C', 'Taiwan Mamenashi' (Pyrus calleryana Dcne.) and 'Seleção IAC-1' (Pyrus spp.) using semi-hardwood cuttings. The experiment was conducted in a nursery with an intermittent mist system at the Propagation Center Laboratory of the Botanical Garden, Instituto Agronômico de Campinas (IAC), SP, Brazil. The experiment was arranged in a 3 x 4 factorial scheme (rootstocks $\mathrm{x}$ indolebutyric acid doses), with five repetitions of 20 cuttings, in a complete randomized design. Results obtained 60 days after grafting showed that: a) the propagation of 'Taiwan Nashi-C', 'Taiwan Mamenashi' and 'Seleção IAC-1' using semi-hardwood cuttings is technically viable; b) among the studied rootstocks, 'Taiwan Nashi-C' showed the highest rooting percentage, lowest callus percentage, highest root length and root number per cutting; c) rooting of semi-hardwood cuttings required application of indolebutyric acid, and the doses $4000 \mathrm{mg} . \mathrm{L}^{-1}$ and $6000 \mathrm{mg} . \mathrm{L}^{-1}$ provided the highest adventitious rooting; d) the tested doses of indolebutyric acid were not phytotoxic to semi hardwood cuttings of the studied genotypes.

Key words: Clonal propagation, cuttings, pear, Pyrus calleriana, Pyrus spp.,

Recebido para publicação em fevereiro de 2010 e aprovado em novembro de 2010

${ }^{1}$ Engenheiro-Agrônomo, Mestre. Pesquisador da EPAGRI, Estação Experimental de Videira, Caixa Postal 21, 89560-000, Videira, SC, Brasil. nelsonfeldberg@epagri.sc.gov.br, * Autor correspondente.

${ }^{2}$ Biólogo, Mestre. Pesquisador do Instituto Agronômico de Campinas (IAC), Agência Paulista de Tecnologia dos Agronegócios (APTA), Centro Experimental Central, Av. Barão de Itapura, 1481, Caixa Postal 28, Guanabara, 13001-970, Campinas, SP, Brasil, wbarbosa@iac.sp.gov.br.

${ }^{3}$ Engenheiro-Agrônomo, Doutor. Pesquisador da Embrapa Clima Temperado, Rodovia BR 392, km 78, Caixa Postal 403, 96001-970, Pelotas, RS, Brasil. alex@cpact.embrapa.br.

${ }^{4}$ Bióloga, Mestre. Bolsista AT, Universidade Federal de Lavras, Campus Universitário, Caixa Postal 3037, 37200-000, Lavras, MG, Brasil. mottinha_fer@yahoo.com.br 


\section{INTRODUÇÃO}

A produção mundial de pêras em 2008 foi de 29.999.195 toneladas, em área colhida de 1.736.819 hectares. O Brasil, com produção de 17391 toneladas, contribuiu com apenas 0,056 \% da produção mundial (FAO, 2010). Devido à pequena produção no Brasil, a pêra lidera o ranking de frutas importadas, com a importação de grandes volumes para atender a demanda interna. Em 2008, o Brasil importou 139.777,53 toneladas de pêras, correspondente à US\$ 120.624.143,00 (IBRAF, 2010).

Em função do aumento contínuo do volume importado pelo país no período entre 2003 e 2008 (IBRAF, 2010), observa-se a necessidade de se desenvolver tecnologias para viabilizar o cultivo da pereira, solucionando os problemas que limitam a expansão em área cultivada e em rentabilidade aos fruticultores. Dentre as demandas, é constante a necessidade de informações relativas à porta-enxertos, pelos efeitos diretos e indiretos que exercem nas copas, além de métodos para viabilizar sua propagação clonal, por garantir a manutenção da identidade genética, homogeneizando seus efeitos nas cultivares-copa (Antunes et al., 1996; Webster, 1998; Faoro \& Yasunobu, 2000; Reis et al., 2000; Chalfun et al., 2002; Wertheim, 2002; Barbosa et al., 2007).

Pyrus calleryana Dcne e P. betulaefolia Bunge são os porta-enxertos mais utilizados para a cultura da pereira no Brasil (Leite, 2000). Estima-se que estejam presentes entre 90 e 95 \% da área total cultivada (Rufato et al., 2004). As plantas de $P$. betulaefolia são bastante vigorosas e têm sido utilizadas como porta-enxertos para cultivares de $P$. communis L., menos vigorosas e que produzem frutas de coloração vermelha, e para as cultivares asiáticas (Camellato, 2003). A espécie P. calleryana apresenta boa adaptação a climas quentes, a solos arenosos ou argilosos, adequada ancoragem, compatibilidade com as cultivares-copa existentes, a tolerância a solos encharcados e resistência a diversas doenças como o declínio e ao "fire blight”. Recentemente, no Brasil, vem sendo avaliada também como porta-enxerto para macieiras e marmeleiros, além das pereiras (Pio et al., 2008).

No Estado de São Paulo, a cultura da pereira vem sendo ampliada com plantios de cultivares japonesas, enxertadas em novos porta-enxertos orientais, como $P$. calleryana e $P$. betulaefolia. O porta-enxerto 'Taiwan Nashi-C' (P. calleryana), clone introduzido do Japão há mais de dez anos, tem apresentado boa adaptação ao clima tropical de altitude, como na região de Jundiaí-SP, que apresenta média histórica anual de 80 horas de frio com temperaturas $<7,0^{\circ} \mathrm{C}$. Além da adaptação aos solos úmidos, a tolerância às principais pragas e doenças, o vigor e o rápido crescimento observado nas plantas matrizes, 'Taiwan Nashi-C' demonstrou ser compatível com mais de 50 cultivarescopa e seleções de pereiras européias, orientais e híbridos (Barbosa et al., 1995).

Em viveiros, os porta-enxertos atingem o ponto de enxertia, entre seis e sete meses após a emergência, quando a maioria mede, aproximadamente, $8 \mathrm{~mm}$ de diâmetro à cerca de $15 \mathrm{~cm}$ acima do nível do solo e $120 \mathrm{~cm}$ de altura (Pio et al., 2007). Além disto, o custo da propagação sexuada é baixo e a conservação das sementes armazenadas a $5-10^{\circ} \mathrm{C}$ é satisfatória, sendo possível obter $94 \%$ de germinação quando elas são armazenadas por 18 meses. Por outro lado, conforme observam Barbosa et al. (1997), aproximadamente $20 \%$ dos seedlings de 'Taiwan NashiC' apresentam-se anormais, com segregação indesejada para a formação de mudas vigorosas de pereira, o que sugere que o uso de métodos de propagação vegetativa seria mais eficiente para evitar o problema.

O porta-enxerto 'Seleção IAC-1', material de origem desconhecida, vem sendo caracterizado há cerca de 10 anos no Instituto Agronômico (IAC). Trata-se de um genótipo que apresenta algumas semelhanças entre a pereira 'Taiwan Nashi-C', como a arquitetura e o vigor das plantas, e a 'Manshu Mamenashi', como a coloração das folhas e a borda serrilhada. A massa dos frutos é intermediária à dos dois genótipos citados. Paralelamente às análises moleculares, iniciou-se sua avaliação como portaenxerto de pereiras asiáticas e européias ${ }^{5}$.

Para estacas lenhosas de $P$. calleryana, Antunes et al. (1996) constataram maior eficiência da imersão rápida (5 segundos) em ácido indolbutírico (AIB), comparativamente à imersão lenta (24 horas). Em imersão rápida, os autores recomendaram a dose de 2.000 mg. L $^{-1}$ de AIB, por aumentar o peso da matéria seca de raízes, em relação às doses 0, 1.000 e 3.000 mg.L -1 $^{-}$O ácido indolbutírico também foi benéfico ao enraizamento de estacas lenhosas de pereira 'Limeira' (Pyrus pyrifolia (Burm F.) Nakai x $P$. communis), sendo os melhores resultados obtidos com a dose de 4.000 mg. $\mathrm{L}^{-1}$, acondicionando-se as estacas em estufa tipo B.O.D. (Biochemical Oxygen Demand) (Barbosa et al., 2007).

Em P. calleryana ' $\mathrm{D}-6$ ', a porcentagem de enraizamento de estacas lenhosas não foi influenciada pelo estiolamento da planta matriz, nem pela bandagem na base dos ramos e uso de 2.000 mg. $\mathrm{L}^{-1}$ de ácido indolbutírico (Chalfun et al., 2002).

O objetivo do presente trabalho foi estudar a viabilidade técnica da propagação vegetativa dos porta-enxertos de pereira 'Taiwan Nashi-C', 'Taiwan Mamenashi' $(P$. calleryana Dcne.) e 'Seleção IAC-1' (Pyrus spp.), por estacas semi-lenhosas.

${ }^{5}$ Barbosa - Comunicação pessoal - 03/12/2008 - Instituto Agronômico (IAC), São Paulo, Brasil 


\section{MATERIAL E MÉTODOS}

Plantas matrizes com 12 anos de idade, dos porta-enxertos de pereira 'Taiwan Nashi-C', 'Taiwan Mamenashi' (P. calleryana Dcne.) e 'Seleção IAC-1' (Pyrus spp.), foram mantidas em condições de campo, em área experimental pertencente ao Pólo Regional do Sudoeste Paulista (APTA), em Capão Bonito-SP.

Em julho de 2006, realizou-se poda drástica nessas plantas, para a indução da brotação de ramos novos. A coleta dos ramos semi-lenhosos foi realizada em 12 de dezembro de 2006. Tais ramos foram embalados em papel umedecido e acondicionados em sacos plásticos, para evitar a desidratação das folhas. Em seguida foram transportados ao Laboratório de Propagação do Núcleo Jardim Botânico, do Instituto Agronômico (IAC), em Campinas$\mathrm{SP}$, onde o experimento foi conduzido.

O delineamento experimental adotado foi o inteiramente casualizado, no esquema fatorial 3 x 4 (porta-enxertos $\mathrm{x}$ concentrações de AIB), com cinco repetições de 20 estacas cada, totalizando 60 parcelas.

As estacas foram preparadas com, aproximadamente, $25 \mathrm{~cm}$ de comprimento, contendo de 4 a 6 gemas e 3 a 4 folhas, deixadas na gema superior. Para 'Taiwan Nashi-C' e 'Seleção IAC-1', as estacas apresentavam diâmetro entre 8 e 12 mm e, para 'Taiwan Mamenashi', entre 10 e 15 $\mathrm{mm}$. Os cortes foram feitos em bisel, sendo o da base da estaca logo abaixo de uma gema, local onde também foram feitas duas lesões opostas, com auxílio de um estilete, conforme método descrito por Murata et al. (2002). Procedeu-se o tratamento da base das estacas com solução hidroalcoólica de ácido indolbutírico (AIB) por cinco segundos, nas seguintes concentrações: 0, 2.000, 4.000 e $6.000 \mathrm{mg} . \mathrm{L}^{-1}$. Em seguida, as estacas foram acondicionadas em sacos plásticos (15 cm de altura x $10 \mathrm{~cm}$ de diâmetro) com furos de $0,6 \mathrm{~cm}$ de diâmetro, contendo vermiculita expandida de grânulos médios, tipo Agrofloc (produzido pela empresa Brasil Minérios), ocultando-se 1/3 da parte basal das estacas no substrato. Os sacos plásticos foram mantidos em ambiente telado (50 \% de sombreamento), equipado com sistema de nebulização intermitente, o qual foi programado para acionar por 1 minuto a nebulização, a cada intervalo de 30 minutos.

Transcorridos 60 dias da estaquia, as estacas foram retiradas da vermiculita, avaliando-se as seguintes variáveis: porcentagem de estacas enraizadas, porcentagem de estacas com calo, porcentagem de estacas mortas e porcentagem de estacas verdes (vivas, porém sem calos e sem raízes). Nas estacas enraizadas, foi avaliado o número de raízes por estaca e o comprimento das três maiores raízes.

Os dados expressos em porcentagem foram transformados para arco seno $\sqrt{\mathrm{p} / 100}$. Os dados foram submeti- dos à análise de variância e teste $\mathrm{F}$ e as médias foram comparadas pelo teste de Tukey, ao nível de 5 \% de probabilidade, utilizando-se o programa Sisvar.

\section{RESULTADOS E DISCUSSÃO}

Ocorreu diferença significativa entre os genótipos de pereira na porcentagem de enraizamento (Tabela 1). O cultivar 'Taiwan Nashi-C' apresentou 49,74\% de enraizamento, diferindo de 'Taiwan Mamenashi’ (27,70\%) e da 'Seleção IAC-1' (30,59 \%). Esses resultados já indicam viabilidade técnica da propagação desses porta-enxertos por estacas semi-lenhosas, pois, na prática, porcentagens de enraizamento ao redor de $50 \%$ tem sido consideradas viáveis comercialmente. Apesar da menor eficiência na obtenção de porta-enxertos, comparativamente ao sistema tradicional por germinação de sementes, o método da estaquia semi-lenhosa apresenta a vantagem da garantia da fidelidade genética da planta matriz e da manutenção do vigor, pré-requisitos da moderna fruticultura. Murata et al. (2002) também observaram diferenças entre porta-enxertos de pereira quanto à capacidade de enraizamento em estacas lenhosas mantidas sob nebulização intermitente, cujo melhor resultado (53,8 \% de enraizamento) também foi obtido com 'Taiwan NashiC', utilizando-se estacas sem corte basal e não tratadas com fitorreguladores. Diferenças entre genótipos, quanto a capacidade de enraizamento, também foram observadas em estacas semi-lenhosas de marmeleiro (Rufato et al., 2004) e entre espécies de Pyrus sp. Entretanto, os resultados não são consistentes entre $P$. betulaefolia e $P$. calleryana. Simonetto (1990) obteve maiores porcentagens de enraizamento com $P$. betulaefolia, tanto com estacas lenhosas como com estacas semi-lenhosas, enquanto que Silva et al. (1997) obtiveram melhores resultados com $P$. calleryana, testando a enxertia e a estaquia lenhosa simultaneamente.

Para a porcentagem de estacas com calo, os três porta-enxertos diferiram entre si (Tabela 1). A menor média foi obtida em ‘Taiwan Nashi-C’ (11,49 \%), em função do maior número de estacas enraizadas, e a maior na 'Seleção IAC-1' (39,87 \%). Dentro de cada dose de ácido indolbutírico testada, verifica-se que a 'Seleção IAC-1' apresenta maior tendência em formar calo, enquanto que 'Taiwan Nashi-C', a menor (Figura 2), ainda que nem sempre as diferenças sejam significativas. Em diversas espécies frutíferas lenhosas, a formação de calo não necessariamente resulta na posterior formação de raízes. Entretanto, para $P$. calleryana, a formação de raízes pode ser precedida da formação de calo, conforme destacado por Simonetto (1990). Segundo o autor, com o transplantio de estacas calejadas, é possível obter enraizamento após a retirada da câmara de nebulização, no viveiro. Portanto, 
com os genótipos estudados no presente trabalho, é possível que a porcentagem de enraizamento possa ser aumentada, hipótese esta que ainda deve ser investigada.

A mortalidade de estacas foi elevada em 'Taiwan Mamenashi’ (47,63\%), diferindo estatisticamente dos demais genótipos, sendo que 'Taiwan Nashi-C' (33,21\%) e 'Seleção IAC-1' (26,54 \%) não diferiram entre si. As estacas de 'Taiwan Mamenashi' foram as que apresentavam os maiores diâmetros no momento da estaquia, devido ao maior vigor de suas plantas em resposta à poda drástica realizada no mês de julho de 2006. Possivelmente, o diâmetro das estacas pode ter influenciado negativamente o enraizamento, sendo necessários novos estudos para verificar se a formação de raízes aumenta quando as estacas são preparadas à partir de ramos mais finos, coletados com menor número de dias após a poda.

As porcentagens de estacas verdes, ou seja, as que não apresentaram formação de raízes ou calo, mas que permaneceram verdes e com folhas, foi considerada baixa nos três genótipos. 'Taiwan Nashi-C' apresentou maior média (5,58 \%) em relação à 'Taiwan Mamenashi’ (0,25 \%). A 'Seleção IAC-1' comportou-se como intermediária, com 3,0 \% de estacas verdes. Essa variável tem sido também avaliada e/ou incluída apenas como porcentagem de estacas não enraizadas, por muitos autores. Entretanto, no presente estudo, com o objetivo de melhor detalhar os efeitos dos fatores e níveis testados, optou-se por classificar as estacas que não formaram raízes em três classes (calo, verdes e mortas). Na prática, entende-se que se durante o período de enraizamento (60 dias) não houver enraizamento ou mesmo formação de calo, dificilmente isso ocorrerá depois. Ou ainda, mesmo que ocorra a formação de raízes, a baixa porcentagem de estacas verdes (5,58 \%) obtida não justificaria sua manutenção em câmara de nebulização intermitente por período maior.

'Taiwan Nashi-C' apresentou melhor qualidade de raízes adventícias em relação aos demais genótipos, comprovada estatisticamente com o maior número de raízes por estaca $(5,36)$ e com maior comprimento $(6,89 \mathrm{~cm})$. Essas variáveis são importantes em trabalhos de propagação vegetativa, pois, juntamente com a porcentagem de enraizamento, revelam a qualidade do sistema radicular formado e expressam os efeitos dos tratamentos testados. O comprimento das raízes e o número de raízes por estaca também são variáveis que se relacionam com a capacidade de sobrevivência das estacas, após a retirada da câmara de nebulização intermitente, quando ocorre a troca do substrato de enraizamento para o de aclimatação e crescimento. Posteriormente, essas variáveis também influenciarão no crescimento dos porta-enxertos, no engrossamento do caule, na época de realização da enxertia, no crescimento e na ancoragem das plantas no campo. O crescimento e o desenvolvimento de uma planta no campo, cujo porta-enxerto é propagado vegetativamente, depende muito da qualidade dos sistema radicular formado na fase de enraizamento, sobretudo o número de raízes primárias e a sua adequada distribuição ao redor da estaca.

Portanto, no conjunto das variáveis analisadas, verifica-se que os melhores resultados foram obtidos com 'T. Nashi-C' que, além da maior porcentagem de enraizamento, apresentou maior número e comprimento de raízes, o que confere melhor qualidade ao sistema radicular primário. 'Taiwan Mamenashi' e a 'Seleção IAC-1' não diferiram entre si, nas variáveis número e comprimento de raízes.

Tabela 1. Efeito do porta-enxerto e do ácido indolbutírico (AIB) no enraizamento de estacas semi-lenhosas de pereiras, em câmara de nebulização intermitente.

\begin{tabular}{|c|c|c|c|c|c|c|}
\hline Porta-enxertos & $\%$ ENR & $\%$ CAL & \% MOR & $\%$ VER & NRE & СОМР \\
\hline 'T. Nashi-C' & $49,74 \mathrm{a}$ & 11,49 c & $33,21 \mathrm{~b}$ & 5,58 a & 5,36 a & 6,89 a \\
\hline ‘T. Mamen.' & $27,70 \mathrm{~b}$ & $24,41 \mathrm{~b}$ & $47,63 \mathrm{a}$ & $0,25 \mathrm{~b}$ & $3,90 \mathrm{~b}$ & $3,32 \mathrm{~b}$ \\
\hline 'Sel. IAC-1' & 30,59 b & 39,87 a & $26,54 \mathrm{~b}$ & $3,00 a b$ & 2,92 b & 4,13 b \\
\hline $\mathrm{F}$ & $11,921 * *$ & $30,865^{* *}$ & $9,267^{*}$ & $6,460 *$ & $12,205^{* *}$ & $34,124 * *$ \\
\hline \multicolumn{7}{|l|}{ AIB } \\
\hline $0 \mathrm{mg} \cdot \mathrm{L}^{-1}$ & $11,44 \mathrm{~b}$ & 45,15 a & $39,71^{\mathrm{NS}}$ & $3,71^{\mathrm{NS}}$ & $1,29 \mathrm{c}$ & $2,14 \mathrm{~b}$ \\
\hline $2.000 \mathrm{mg} . \mathrm{L}^{-1}$ & 34,57 a & $28,08 \mathrm{~b}$ & 33,29 & 4,06 & $3,91 \mathrm{~b}$ & 5,35 a \\
\hline $4.000 \mathrm{mg} . \mathrm{L}^{-1}$ & 50,05 a & 16,27 bc & 32,69 & 1,00 & $5,19 a b$ & $5,74 \mathrm{a}$ \\
\hline $6.000 \mathrm{mg} . \mathrm{L}^{-1}$ & 47,98 a & 11,53 с & 37,48 & 3,00 & 5,83 a & 5,88 a \\
\hline $\mathrm{F}$ & $22,544 * *$ & $22,412 * *$ & 0,801 NS & 1,911 Ns & $24,606^{* *}$ & $22,967 * *$ \\
\hline$F_{\text {p-enx. x AIB }}$ & $1,416^{\mathrm{NS}}$ & 1,641 Ns & 0,695 Ns & 1,398 Ns & 0,282 NS & 0,980 NS \\
\hline$\overline{C V}(\%)$ & 31,43 & 34,69 & 25,22 & 144,04 & 38,65 & 29,98 \\
\hline
\end{tabular}

Médias seguidas por letras distintas, na mesma coluna, diferem entre si pelo teste de Tukey. *significativo ao nível de 5 \% de probabilidade; **significativo ao nível de $1 \%$ de probabilidade; NS não significativo. \% ENR: porcentagem de estacas enraizadas; \% CAL: porcentagem de estacas com calo; \% MOR: porcentagem de estacas mortas; \% VER: porcentagem de estacas verdes (vivas, sem formação de raízes ou calo); NRE: numero de raízes por estaca; COMP: comprimento das três maiores raízes (cm). 
O uso do ácido indolbutírico foi benéfico às estacas semi-lenhosas dos genótipos estudados (Tabela 1 ), pois promoveu o aumento da porcentagem de enraizamento, do número de raízes por estaca e do comprimento das raízes. As doses de 2.000, 4.000 e de 6.000 mg. $L^{-1}$ não exerceram influência significativa na porcentagem de enraizamento, para ' $T$. Nashi-C' e ' $T$. Mamenashi'. Já para a 'Seleção IAC-1', as doses de 4.000 e de 6.000 não diferiram entre si, porém influenciaram positivamente no enraizamento, comparativamente às doses 2.000 e 0 mg.L $\mathrm{L}^{-1}$ (Figura 1 ).

Para as variáveis número de raízes por estaca e comprimento médio das raízes, não houve diferença significativa entre as doses 2.000 , 4.000 e 6.000 mg. $\mathrm{L}^{-1}$, para nenhum dos três porta-enxertos estudados (Figuras 3 e 4). Apesar da não significância, constata-se que as doses de 4.000 e de 6.000 mg. $\mathrm{L}^{-1}$ tendem a promover melhorias na qualidade do sistema radicular, compara- tivamente à dose de $2.000 \mathrm{mg} \cdot \mathrm{L}^{-1}$. Em estacas lenhosas de Pyrus calleryana, o enraizamento adventício não é influenciado pelo estiolamento da planta matriz e nem pelo uso de $2.000 \mathrm{mg} . \mathrm{L}^{-1}$ de AIB (Reis et al., 2000). Antunes et al. (1996) também não constataram efeito significativo do uso AIB na porcentagem de enraizamento de estacas semi-lenhosas da mesma espécie. Entretanto, segundo Simonetto (1990), doses de 2.000, 3.000 ou 4.000 mg. L $^{-1}$ promoveram enraizamento em torno de $30 \%$ em estacas semi-lenhosas de P. calleryana, enquanto que na ausência de AIB, o enraizamento foi de apenas $8,1 \%$. No enraizamento in vitro, tanto para P. calleryana como para P. betulaefolia, a maior concentração de AIB testada (1,0 mg. $\left.\mathrm{L}^{-1}\right)$ apresentou o melhor resultado (100 \% de enraizamento), em brotos com ou sem ranhuras na base, mantidos em meio Murashige \& Skoog (MS) (Pasqual \& Lopes, 1991; Pasqual et al., 2002).

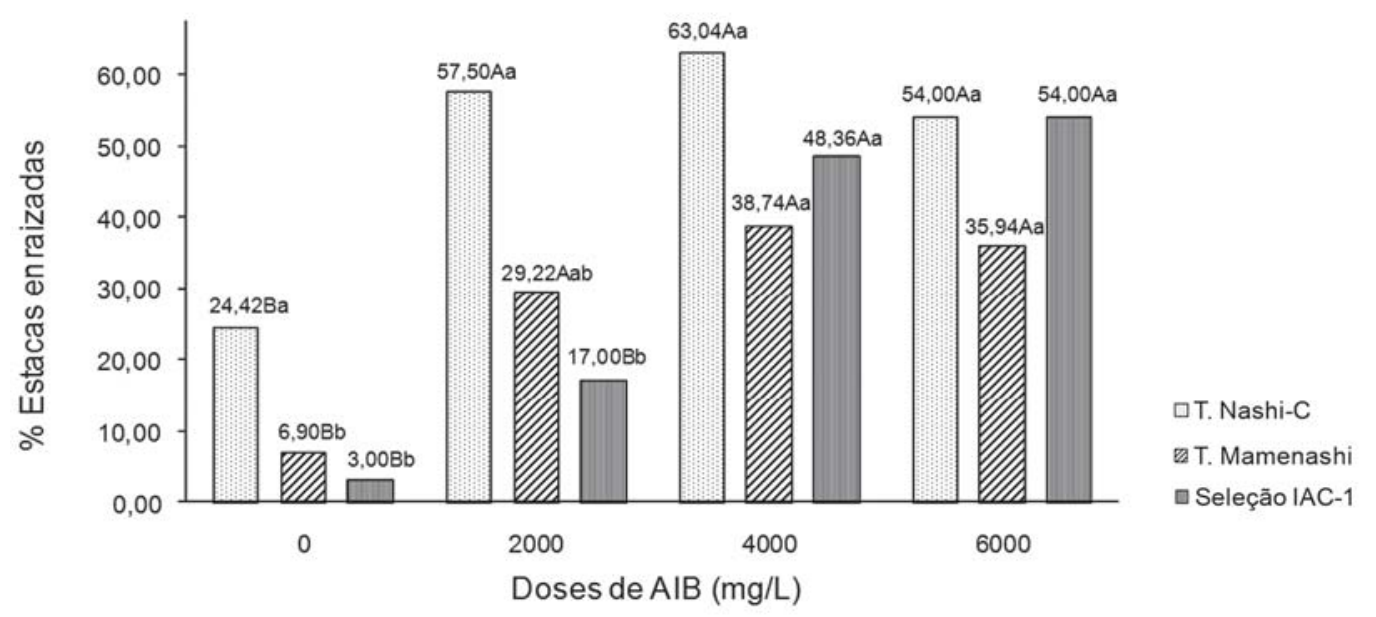

Figura 1. Porcentagem de estacas de porta-enxertos de pereira tratadas com diferentes doses de ácido indolbutírico (AIB) e enraizadas. Letras maiúsculas distintas indicam respostas diferentes às doses de AIB para o mesmo porta-enxerto e letras minúsculas distintas indicam diferenças entre os porta-enxertos dentro da mesma dose de AIB, segundo o teste de Tukey a $5 \%$ de probabilidade.

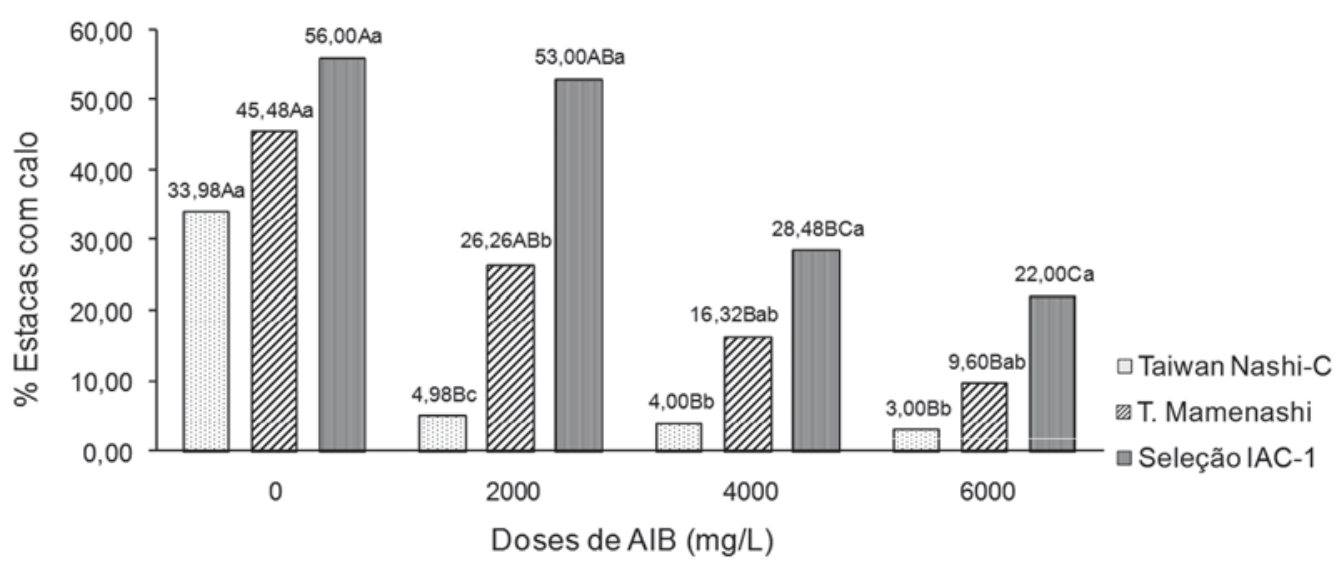

Figura 2. Porcentagem de estacas de porta-enxertos de pereira tratadas com diferentes doses de ácido indolbutírico (AIB) com calo. Letras maiúsculas distintas indicam respostas diferentes às doses de AIB para um mesmo porta-enxerto; letras minúsculas distintas indicam diferenças entre os porta-enxertos dentro de uma mesma dose de AIB, pelo teste de Tukey a $5 \%$ de probabilidade. 
Dentro de cada dose de ácido indolbutírico testada, diferenças foram observadas entre os porta-enxertos nas variáveis número de raízes por estaca (Figura 3) e comprimento médio das raízes (Figura 4). Para a primeira variável, ‘Taiwan Nashi-C’ apresentou número de raízes significativamente maior apenas em relação à 'Seleção IAC-1' e nas doses 2.000 e 6.000 mg. $\mathrm{L}^{-1}$. Na variável comprimento de raízes, 'Taiwan Nashi-C' novamente se destacou em relação aos demais porta-enxertos nas quatro doses de ácido indolbutírico testadas, pois suas raízes apresentaram comprimento significativamente maior que os demais. Esses dados revelam melhor qualidade de raízes do portaenxerto ‘Taiwan Nashi-C’ e maior chance de sobrevivência na fase subseqüente (aclimatação).

Outro benefício do uso do AIB foi a redução da porcentagem de estacas com calo, comparando-se com as estacas não tratadas com o fitorregulador (Tabela 1; Figura 2). As doses do AIB apresentaram efeito inversa- mente proporcional à formação de calo, ou seja, na ausência de AIB a porcentagem de estacas com calo foi maior (45,15 \%) e com o aumento da dose de AIB, a porcentagem de estacas com calo foi gradativamente reduzida (Figura 2), atingindo 11,53 \% na dose de 6.000 mg.L${ }^{1}$ (Tabela 1).

As doses de AIB não exerceram efeito significativo nas porcentagens de mortalidade e de estacas verdes (Tabela 1). Portanto, verifica-se que nenhuma das três doses de ácido indolbutírico testadas apresentou efeito fitotóxico, pois não provocaram a mortalidade das estacas e foram equivalentes à testemunha.

São necessários estudos complementares para a avaliação do comportamento produtivo das principais cultivares-copa enxertadas sobre esses porta-enxertos, bem como sua utilização com interenxerto de menor vigor, visando reduzir o porte das plantas e antecipar a entrada em produção.

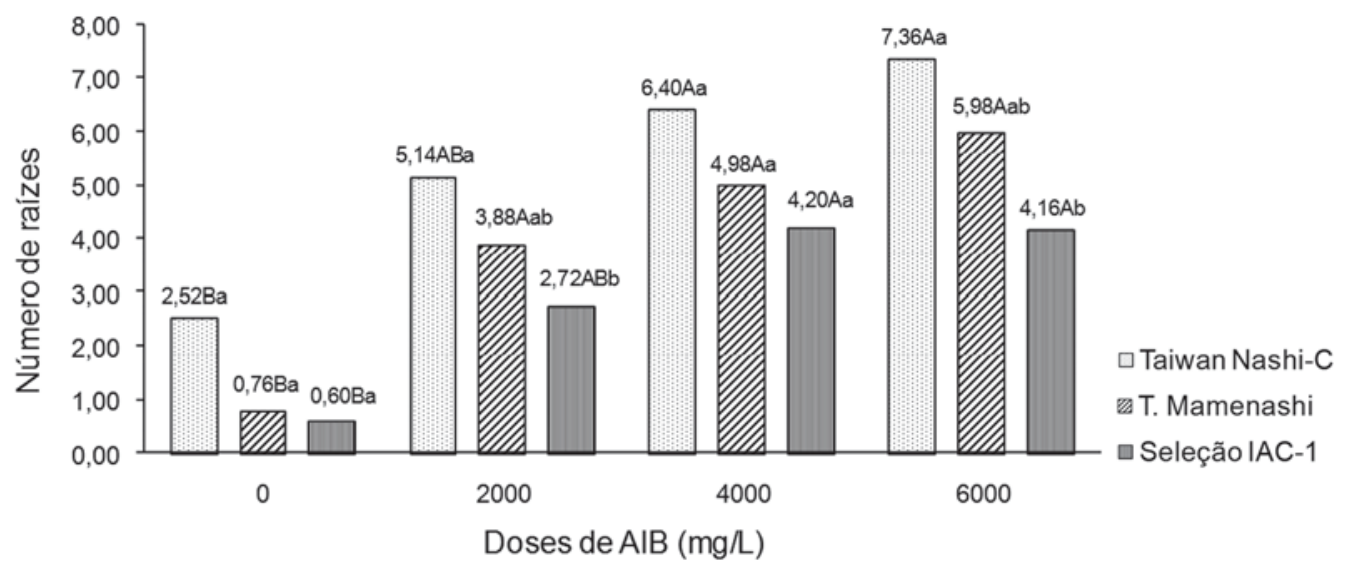

Figura 3. Número de raízes por estaca de porta-enxertos de pereira tratada com diferentes doses de ácido indolbutírico (AIB). Letras maiúsculas distintas indicam respostas diferentes às doses de AIB para um mesmo porta-enxerto; letras minúsculas distintas indicam diferenças entre os porta-enxertos dentro de uma mesma dose de AIB, pelo teste de Tukey a 5 \% de probabilidade.

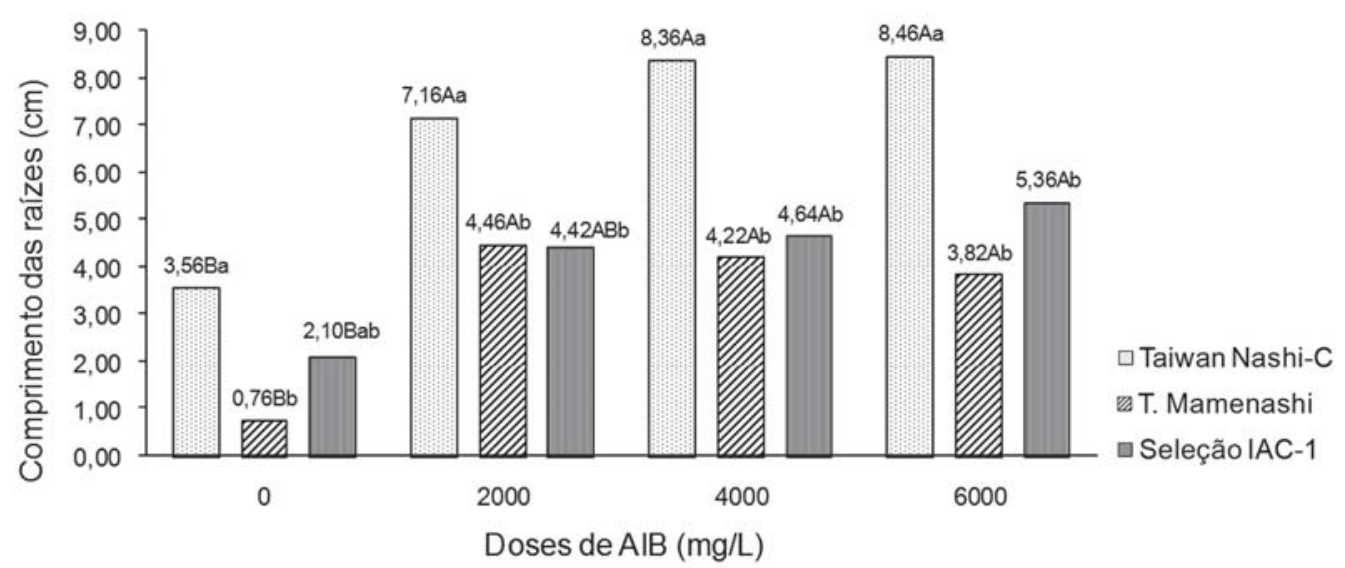

Figura 4. Comprimento médio das raízes em estacas de porta-enxertos de pereira tratadas com diferentes doses de ácido indolbutírico (AIB). Letras maiúsculas distintas indicam respostas diferentes às doses de AIB para um mesmo porta-enxerto; letras minúsculas distintas indicam diferenças entre os porta-enxertos dentro de uma mesma dose de AIB, pelo teste de Tukey a $5 \%$ de probabilidade. 


\section{CONCLUSÕES}

É tecnicamente possível a propagação dos porta-enxertos ‘Taiwan Nashi-C', 'Taiwan Mamenashi’ e 'Seleção IAC-1' por estacas semi-lenhosas, sob câmara de nebulização intermitente.

Dentre os porta-enxertos estudados, 'Taiwan Nashi-C' apresenta a maior porcentagem de enraizamento, a menor porcentagem de estacas com calo, além do maior comprimento de raízes e número de raízes por estaca.

É necessário o uso de ácido indolbutírico para o enraizamento de estacas semi-lenhosas dos porta-enxertos estudados, sendo que, no conjunto das variáveis analisadas, as doses de 4.000 mg.L $L^{-1}$ e de 6.000 mg. L $^{-1}$ proporcionam os maiores benefícios ao enraizamento adventício.

As doses de ácido indolbutírico testadas não são fitotóxicas às estacas semi-lenhosas dos genótipos estudados.

\section{REFERÊNCIAS}

Antunes LEC, Hoffmann A, Ramos JD, Chalfun NNJ \& Oliveira Júnior AF (1996). Efeito do método de aplicação e de concentrações do ácido indolbutírico no enraizamento de estacas semilenhosas de Pyrus calleryana. Revista Brasileira de Fruticultura, 18:371-376.

Barbosa W, Campo Dall’Orto FA, Ojima M, Novo MCSS, Betti JA \& Martins, FP (1997). Conservação e germinação de sementes e desenvolvimento de plântulas da pereira porta-enxerto 'Taiwan Nashi-C’. Scientia Agrícola, 54:147-151.

Barbosa W, Pio R, Feldberg, NP, Chagas, EA \& Veiga RFA (2007). Enraizamento de estacas lenhosas de pereira tratadas com AIB e mantidas em ambiente de estufa tipo B.O.D. e de telado. Revista Brasileira de Fruticultura, 29:589-594.

Barbosa W, Campo-Dall’Orto FA, Ojima M \& Martins FP (1995). Comportamento da pereira porta-enxerto Taiwan Nashi-C em Jundiaí, SP. In: Simpósio Nacional de Recursos Genéticos Vegetais, Campinas. Anais, p.61.

Camellato D (2003). Propagação. In: Nakasu BH, Quezada AC \& Herter FG. Pêra. Produção. Pelotas, Embrapa Clima Temperado; Brasília, Embrapa Informação Tecnológica, p.37-45.

Chalfun NNJ, Reis JMR, Pasqual M, Bianchi VJ, Cavalcante-Alves JM \& Dutra LF (2002). Rooting of hardwood cuttings of Pyrus calleryana in response to shading, opaque wrapping, and IBA. Acta Horticulturae, 596:451-452.

FAO - Organización De Las Naciones Unidas Para La Agricultura y La Alimentación (2010). Peras: producción, área y rendimiento. Disponível em: <http:// http://faostat.fao.org/site/ 567/DesktopDefault.aspx?PageID=567\#ancor $>$. Acessado em 05 dezembro de 2010.

Faoro ID \& Yasunobu Y (2000). Porta-enxertos e cultivares. In: Faoro ID (Coord.). Curso sobre a cultura da pereira. Caçador, EPAGRI. p.18-31.

IBRAF (2010). Frutas frescas - Importação. Disponível em: $<$ w w w.ibraf.org.br/e s t a tis t i c a s/I m p ortação/ ComparativoImportacoes BrasileirasFrutasFrescas 20082007.pdf>. Acessado em: 05 de dezembro de 2010.

Leite GB (2000). Propagação da pereira. In: Curso sobre a cultura da pereira, 2. Caçador, EPAGRI. 88p.
Murata IM, Barbosa W, Neves CSVJ \& Franco JAM (2002). Enraizamento de estacas lenhosas de porta-enxertos de pereira sob nebulização intermitente. Revista Brasileira de Fruticultura, 24:583-585.

Pasqual M \& Lopes PA (1991). Influência de diversos fatores sobre o enraizamento do porta-enxerto de pereira (Pyrus calleryana) in vitro. Pesquisa Agropecuária Brasileira, 26:331334.

Pasqual M, Cavalcante-Alves JM, Bianchi VJ, Chalfun NNJ, Silva AB \& Dutra LF (2002). In vitro rooting and shoot growth of Pyrus betulaefolia rootstock. Acta Horticulturae, 596:447-450.

Pio R, Chagas EA, Barbosa W, Campo Dall’Orto FA, Signorini G \& Tecchio MA (2007). Substratos para a produção dos portaenxertos para pereiras 'Taiwan Nashi-C' e 'Taiwan Mamenashi' (Pyrus calleryana Dcne.). Bioscience Journal, 23:82-87.

Pio R, Chagas EA, Barbosa W, Tombolato AFC \& Feldberg NP (2008). Interspecific and intergeneric pear, apple and quince grafting using Pyrus calleryana as rootstock. Acta Horticulturae, 800:713-717.

Reis JMR, Chalfun NNJ, Lima LCO \& Lima LC (2000). Efeito do estiolamento e do ácido indolbutírico no enraizamento de estacas do porta-enxerto Pyrus calleryana Dcne. Ciência Agrotecnologia, 24:931-938.

Silva ESB, Finardi NL \& Fortes GRL (1997). Época de enxertia no enraizamento e união do enxerto sobre os porta-enxertos Pyrus calleryana e Pyrus betulaefolia através da enxertia e enraizamento simultâneos. Revista Brasileira de Agrociência, 3:119-124.

Simonetto PR (1990). Propagação de Pyrus calleryana Dcne e Pyrus betulaefolia Bunge, porta-enxertos para pereira, através do processo de estaquia. Dissertação de Mestrado. Faculdade de Agronomia Eliseu Maciel, Universidade Federal de Pelotas, Pelotas, 59p.

Rufato L, De Rossi A, Giacobbo CL \& Fachinello JC (2004). Vegetative propagation of seven quince cultivars for utilization as pear rootstocks in Brazil. Acta Horticulturae, 658: 667-671.

Webster AD (1998). A brief review of pear rootstock development. Acta Horticulturae, 475:135-141.

Wertheim SJ (2002). Rootstocks for European Pear: a Review. Acta Horticulturae, 596:299-309.

Rev. Ceres, Viçosa, v. 57, n.6, p. 810-816, nov/dez, 2010 